\title{
In Vitro Antioxidant Effect of Watermelon Seeds and Effect of its Oil on Serum Lipid Profile of Albino Rats
}

\author{
Asogwa KK ${ }^{1}$, Ani $\mathrm{ON}^{2 *}$, Ubaoji $\mathrm{KI}^{1}$, Enemali $\mathrm{MO}^{1}$ and Onuoha $\mathrm{PN}^{1}$ \\ ${ }^{1}$ Department of Applied Biochemistry, Faculty of Biosciences, Nnamdi Azikiwe University, \\ Awka, Nigeria \\ ${ }^{2}$ Department of Applied Biochemistry, Faculty of Applied Natural Sciences, Enugu State \\ University of Science and Technology, Nigeria
}

*Corresponding author: Ani Onuabuchi Nnenna, Department of Applied Biochemistry, Faculty of Applied Natural Sciences, Enugu State University of Science and Technology, Enugu State, Nigeria, Tel: +234 803778 2410; Email: nnenna.ani@esut.edu.ng

\section{Abstract}

Dyslipidemia is a traditional risk factor for atherosclerosis development. It is associated closely with increased endothelial production of reactive oxygen species. Oxidative stress play a major part in the development of chronic and degenerative ailments such as cancer, autoimmune disorders, rheumatoid arthritis, cataract, ageing, cardiovascular and degenerative disease. In this study, the in vitro antioxidant effect of the ethanol extract of watermelon seed and the effect of watermelon seed oil on serum lipid profile of albino wistar rats was evaluated using standard methods. A total of 24 rats were used for the animal study. The animals were grouped into four of 6 rats each. Group ' $A$ ' served as the negative control and received normal feed with distilled water throughout the period of the experiment. Groups B, C and D received feed mixed with the watermelon seed oil at a ratio of $2 \%, 5 \%$ and $10 \%$ oil respectively. The results showed that the ethanol extract of watermelon seed scavenges free radicals with \% RSA of $46.8 \%$ at a concentration of $500 \mu \mathrm{g} / \mathrm{ml}$ which is comparable with that of BHA, a standard antioxidant (48.9\%). It also has a ferric reducing capacity and ability to inhibit lipid peroxidation. The results obtained may be attributed to the high polyphenol content of water melon seed. From the result of animal studies, the oil reduced the LDL-c and increased HDL-c. This could be as a result of the unsaturated fatty acid and tocotrienol content of the oil. These results suggest that watermelon seed, when consumed along with watermelon fruit, could help in the management of obesity and prevention of lipid related diseases.

Keywords: In vitro antioxidant; Watermelon seed; Seed oil; Lipid profile

Abbreviations: HDL: High density lipoprotein; ROS: reactive oxygen species; DPPH: 2-Diphenyl-1-Picryl Hydrazyl Radical; BHA: Butylatedhydroxy Anisole; TBARS: Thiobarbituric Acid Reactive Substance.

\section{Introduction}

One of the most common risk factors in patients with cardiovascular disease is dyslipidemia. It is an abnormal metabolic status leading to persistent high plasma concentration of lipids [1]. It contributes to the development of atherosclerosis. There is a relationship between lipid metabolic dysfunction in obesity and liver cancer [2]. Compared with other normal cells of organs across the whole body, epithelial cells of normal prostate have higher cholesterol content and during the progression of prostate cancer, the cholesterol content gets even higher, this indicates that the accumulation of cholesterol may contribute to the malignant conversion of prostate [2]. High density lipoprotein (HDL) cholesterol can transport cholesterol from cells to the liver and other steroidogenic organs, and has anti-inflammatory and antioxidant functions, and may 


\section{International Journal of Biochemistry \& Physiology}

reduce growth and progression activity of prostate cancer. High level of triglycerides has also been demonstrated to be responsible for prostate cancer development by elevating oxidative stress and insulin resistance [2].

Oxidative stress plays a major part in the development of chronic and degenerative ailments such as cancer, autoimmune disorders, rheumatoid arthritis, cataract, ageing, cardiovascular and degenerative disease [3,4]. Dyslipidemia is a traditional risk factor for atherosclerosis development; it is associated closely with increased endothelial production of reactive oxygen species (ROS) [5]. Though ROS may come from endogenous sources through normal physiological and metabolic processes such as mitochondria respiration, it could also result from exogenous sources such as exposure to pollutants and ionizing radiation [6]. Peroxidation of lipids exposed to oxygen is responsible for damage to tissues in vivo, where it may cause cancer, inflammatory diseases, atherosclerosis, and ageing. The effects are considered to be caused by free radicals ( $\mathrm{ROO}, \mathrm{RO}, \mathrm{OH}$ ) that are produced during peroxide formation from fatty acids containing methylene-interrupted double bonds (polyunsaturated fatty acids). Lipid peroxidation provides a continuous supply of free radicals that initiate further peroxidation [7]. Lipid peroxidation initiate series of events in vitro that eventually lead to enhanced uptake of low density lipoprotein by macrophages and formation of lipid laden foam cells, one of the earliest atherosclerotic lesions in the arterial intima [8].

Lipid profile or lipid panel is a panel of blood tests that serves as an initial broad medical screening tool for abnormalities in lipids such as cholesterol and triglycerides. The results of this test can identify certain genetic diseases and can determine approximate risks for cardiovascular disease, certain forms of pancreatitis and other diseases [9]. Serum lipid profile is measured for cardiovascular risk prediction. The test includes four basic parameters: Total Cholesterol, HDL cholesterol, LDL cholesterol and triglycerides.

Water melon (Citrullus lanatus) is a tropical fruit which belongs to the family Cucurbitacene. It is a flowering plant originally from South Africa, which is a special kind. It is called water melon in English, Tamil in Kumatipalan and Semangha Tagalog in Indonesia. It is commonly used to make variety of salad notably fruit salad [10].

Water melon seed oil is highly nutritious oil obtained from water melon seed. It is extracted using traditional methods and used as cosmetic ingredient, hence its skin moisturizing function. The fruit is native to Africa and the local people have devised many uses for its seed oil. The seeds are thick and come in many shades of color but are generally black. However, majority of the consumers of watermelon eat only the reddish pulp which is rich in water while the seeds are discarded. Research has shown that the consumption or application of the seed oil serves several functions which includes; anti-inflammatory and detoxifying functions. They are the power house of nutrition with high concentration of dietary minerals, some of these nutrients pass into the seed oil [11]. Thus, the aim of this research is to investigate the effect of the watermelon seed oil on the serum lipid profile of albino rats.

\section{Methodology}

\section{Collection and Identification of Sample}

The sample, watermelon was purchased from Ogbête Main market Enugu, in Enugu state Nigeria, and was authenticated at the department of Botany, Nnamdi Azikiwe University, Awka. It was washed and cut with kitchen knife and the seeds were extracted from the pulp and dried under the sun for 5 days. The seeds were ground using Corona Blender and was stored in an airtight container till further use.

\section{Sample Extraction}

Two hundred grams (200 g) of the ground sample was soaked in $2 \mathrm{~L}$ of $70 \%$ ethanol and was allowed to stand for $48 \mathrm{~h}$ at room temperature with intermittent stirring. The mixture was filtered through a 3-layer muslin cloth and then with whatman paper No. 4 with the aid of a vacuum filter. The filtrate was evaporated at $60^{\circ} \mathrm{C}$ using a water bath (Techmel and Techmel, 420. USA). The dried residue was weighed and reconstituted in $70 \%$ ethanol at a concentration of $10 \mathrm{mg} / \mathrm{ml}$ and stored at $4^{\circ} \mathrm{C}$ in a refrigerator till further use.

\section{Seed Oil Extraction}

The oil was extracted using soxhelet extraction method. Successively, 100g of the ground seed was wrapped in a thimble and placed in the distillation column of the soxhelet apparatus. A volume of $350 \mathrm{ml}$ of $\mathrm{n}$-Hexane was placed in a round bottom flask and the whole apparatus was setup in a heating mantle and allowed to distill for $8 \mathrm{~h}$. The procedure was repeated for the remaining sample and the whole oil extracted was collected by evaporating the $n$-hexane in the flask using a water bath. The oil was further dried in an Oven at $60^{\circ} \mathrm{C}$ and was used in the animal studies.

\section{DPPH Scavenging Activity Assay}

The stable 2, 2-diphenyl-1-picryl hydrazyl radical (DPPH) was used for the determination of free radical scavenging activity of the ethanol extract of the water melon seeds. This was assayed using the method of [12]. An aliquot, $0.3 \mathrm{ml}$ of 


\section{International Journal of Biochemistry \& Physiology}

different concentrations of the extract $(0-500 \mu \mathrm{g} / \mathrm{ml})$ were mixed with $2.7 \mathrm{ml}$ of methanol solution of DPPH $(100 \mu \mathrm{M})$ in test tubes. The mixture was shaken and kept in dark for 60 mins. The absorbance was taken at a wavelength of 517 nM using spectrophotometer. BHA was used as standard. The percentage scavenging activity (RSA) was calculated using the formula:

\section{$\% \mathrm{RSA}=\left[\left(\mathrm{A}_{\mathrm{DPPH}}-\mathrm{A}_{\mathrm{s}}\right) / \mathrm{A}_{\mathrm{DPPH}}\right] \times \mathbf{1 0 0}$}

Where $A_{s}$ is the absorbance of the test solution with the sample and $A_{D P P H}$ is the absorbance of DPPH solution. The EC50 (concentration of sample at 50\% RSA) was calculated from the graph of \% RSA against the sample concentration.

\section{Reducing Power Capacity Assay}

The reducing power was determined according to the method of Barros, et al. [6]. This method is based on the principle of increase in the absorbance of the reaction mixture.

The sample extract, $2.5 \mathrm{ml}$ of various concentrations of ethanol seed extract of Citrullus lanatus $(0-500 \mu \mathrm{g} / \mathrm{ml})$ was mixed with $2.5 \mathrm{ml}$ of $0.2 \mathrm{M}$ sodium phosphate buffer ( $\mathrm{pH} 6.6$ ) and $2.5 \mathrm{ml}$ of $1 \%$ potassium ferricyanide. The mixture was incubated at $50^{\circ} \mathrm{C}$ for 20 mins. $2.5 \mathrm{ml}$ of $10 \%$ Trichloroacetic acid was added and the mixture centrifuged at $1000 \mathrm{rpm}$ for 8 $\mathrm{min}$. The upper layer $(5 \mathrm{ml})$ was mixed with $5 \mathrm{ml}$ of deionised water followed by the addition of $1 \mathrm{ml}$ of $0.1 \%$ ferric chloride. The absorbance was measured at $700 \mathrm{nM}$. The graph of absorbance at $700 \mathrm{nM}$ against the extract concentrations was plotted. Butylated Hydroxyanisole (BHA) was used as a standard antioxidant.

\section{Assay of Inhibition of Lipid Peroxidation}

This was determined by the method of Barros, et al. [6]. Determination of the extent of inhibition of lipid peroxidation was carried out using homogenate of the brain of a goat. The brain was gotten from a goat of approximately $75 \mathrm{~kg}$ body weight purchased from Amansea Slaughter Awka. The brain was dissected and homogenized with pestle and mortar in an ice cold Tris- $\mathrm{HCl}$ buffer ( $\mathrm{pH} 7.4,20 \mathrm{mM}$ ) to produce $10 \%$ $\mathrm{w} / \mathrm{v}$ brain homogenate which was centrifuged at $3000 \mathrm{~g}$ for $10 \mathrm{~min}$. An aliquot $(0.1 \mathrm{ml})$ of the supernatant was incubated with $0.2 \mathrm{ml}$ of the watermelon seed extract at various concentrations $(0-1000 \mu \mathrm{g} / \mathrm{ml})$, in the presence of $0.1 \mathrm{ml}$ of $10 \mu \mathrm{M}$ ferrosulphate and $0.1 \mathrm{ml}$ of $0.1 \mathrm{mM}$ ascorbic acid at $37^{\circ} \mathrm{C}$ for $1 \mathrm{~h}$. The reaction was stopped by the addition of 0.5 $\mathrm{ml}$ of $28 \%$ TCA followed by the addition of $0.38 \mathrm{ml}$ of $2 \%$ TBA. The mixture was then heated at $80^{\circ} \mathrm{C}$ for $20 \mathrm{~min}$. After centrifugation at $3000 \mathrm{~g}$ for $10 \mathrm{~min}$ to remove the protein, the colour intensity of the malondialdehyde (MDA)-TBA complex in the supernatant was measured by its absorbance at $532 \mathrm{nM}$. The inhibition ratio (\%) was calculated using the following formula:

\section{Inhibition ratio (IR) $(\%)=[(A-B) / A] \times 100 \%$}

Where $\mathrm{A}$ and $\mathrm{B}$ were the absorbance of the control and the compound solution respectively. The extract concentration providing 50\% lipid peroxidation inhibition (EC 50) was calculated from the graph of antioxidant activity percentage against the extract concentrations. BHA was used as the standard.

\section{Animal Study}

A total of 24 Wistar albino rats were obtained from the animal house of Applied Biochemistry Department, Nnamdi Azikiwe University, Awka. They were acclimatized for one week during which they were fed with standard feed and distilled water ad libitum. At the end of the one week, the animals were weighed and grouped into four of six rats each.

Group A: This is the control group. They were fed with standard feed and distilled water.

Group B: this group was fed with feed containing 2\% of water melon seed oil and distilled water.

Group C. this group was fed with feed containing 5\% of water melon seed oil and distilled water.

Group D. this group was fed with feed containing $10 \%$ of watermelon seed oil and distilled water

The administration lasted for 21 days. The animals were monitored closely every day. At the end of the experimental period, after an overnight fast, the animals were sacrificed and blood samples were collected by cardiac puncture for lipid profile assay.

\section{Assays of Lipid Profile}

This was determined according to the method of Sidhu and Naugler [13] with slight modification.

\section{Total Cholesterol}

The cholesterol content of the serum was measured at $546 \mathrm{~nm}$ using Autochemistry Analyser (Mindray BA-88). The cholesterol was determined after enzymatic hydrolysis and oxidation. The serum $(5 \mu \mathrm{L})$ was mixed with $500 \mu \mathrm{L}$ of Mindray Cholesterol reagent and allowed to stand for $10 \mathrm{mins}$ at room temperature after which the total cholesterol content (mg/dl) was measured using Auto chemistry analyzer.

Triglyceride: The Triglyceride content of the serum was measured at $546 \mathrm{~nm}$ using Autochemistry Analyser (Mindray BA-88).

The serum $(5 \mu \mathrm{L})$ was mixed with $500 \mu \mathrm{L}$ of Mindray 


\section{International Journal of Biochemistry \& Physiology}

Triglyceride reagent and allowed to stand for 10 mins at room temperature after which the Triglyceride content was measured using Auto chemistry analyzer.

\section{LDL-c}

This was determined by measuring the amount of cholesterol remaining in the serum after precipitation with polyvinyl sulphate. The LDL content is the difference between the total cholesterol and the cholesterol remaining in solution after precipitation. The serum $(200 \mu \mathrm{L})$ was mixed with $500 \mu \mathrm{L}$ of polyvinyl sulphate reagent and allowed to stand for $10 \mathrm{mins}$ at room temperature. It was then centrifuged at $4000 \mathrm{rpm}$ for $10 \mathrm{mins}$. The supernatant $(100 \mu \mathrm{L})$ was mixed with $500 \mu \mathrm{L}$ of cholesterol reagent and allowed to stand for $10 \mathrm{mins}$ after which the LDL content (mg/dl) was measured using Auto chemistry analyzer.

\section{HDL -c}

This was determined by measuring the amount of cholesterol remaining in the serum after precipitation of LDL, VLDL and Chylomicron by the addition of phosphotungstic acid and magnesium chloride. The HDL content was measured as the remaining cholesterol in the sample solution after precipitation. The serum $(200 \mu \mathrm{L})$ was mixed with $500 \mu \mathrm{L}$ of HDL reagent and allowed to stand for $10 \mathrm{mins}$ at room temperature. It was then centrifuged at 4000rpm for 10 mins. The supernatant $(100 \mu \mathrm{L})$ was mixed with $500 \mu \mathrm{L}$ of cholesterol reagent and allowed to stand for $10 \mathrm{mins}$ after which the HDL content was measured using Auto chemistry analyzer.

\section{Statistics}

The results obtained were analysed using ANOVA on SPSS version 17.0

\section{Results}

\section{DPPH Free Radical Scavenging Activity}

The results of DPPH radical scavenging activity of the ethanol extract of watermelon seeds and the standard antioxidants (BHA) are presented in Figure 1 below. The seed extract and the standard antioxidants promoted an inhibition of DPPH radical with increasing concentrations. However, the percentage inhibition of the DPPH radical by the seed extract was significantly higher $(\mathrm{p}<0.05)$ than that of the standard antioxidant at a lower concentration, but there was no significance in their activities at a higher concentration $\left(300-500 \mu \mathrm{g}\right.$ ). The $\mathrm{EC}_{50}$ (concentration that inhibits $50 \%$ of the DPPH radical) values of the extract is
$369.06 \mu \mathrm{g}$ while that of BHA is $512.23 \mu \mathrm{g}$.

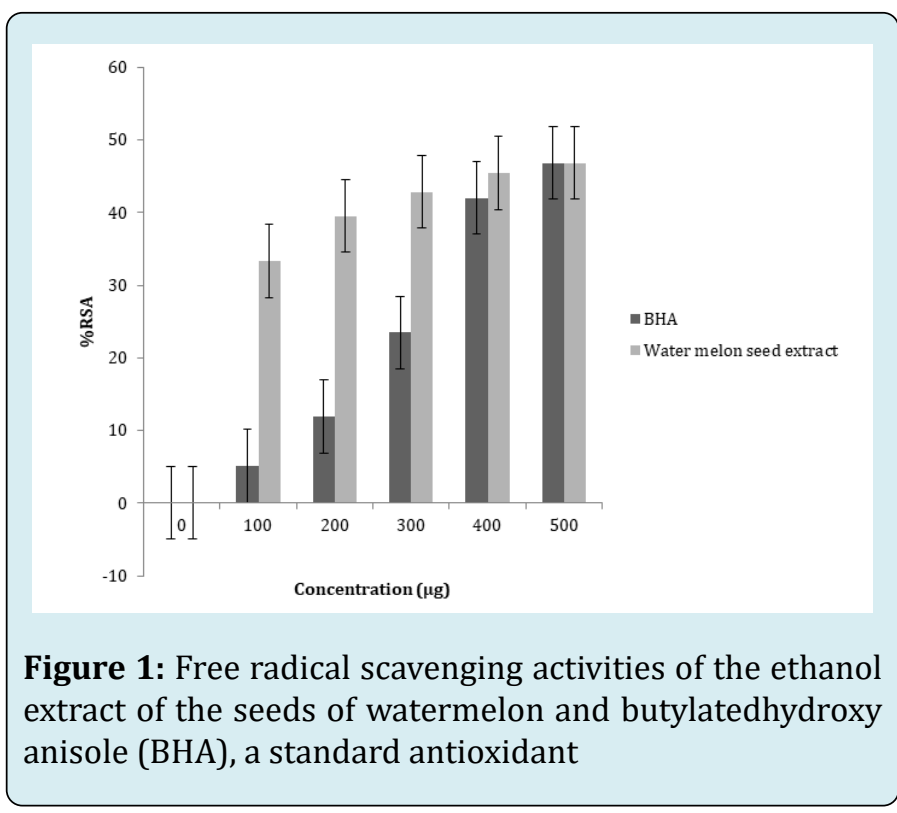

\section{Reducing Power Capacity}

Figure 2 shows the reducing power capacity of the ethanol extract of watermelon seeds and Butylated hydroxyanisole (BHA). The standard antioxidant, BHA, showed better reducing power ability as seen in the sharp rise in absorbance as the concentration increases. The seed extract also displayed a good reducing power potential, though at lower concentration $(100-300 \mu \mathrm{g})$ the activity was lower than that of the standard antioxidant, however, at higher concentration, there was no significant difference $(p>0.05)$ in their reducing power capacity.

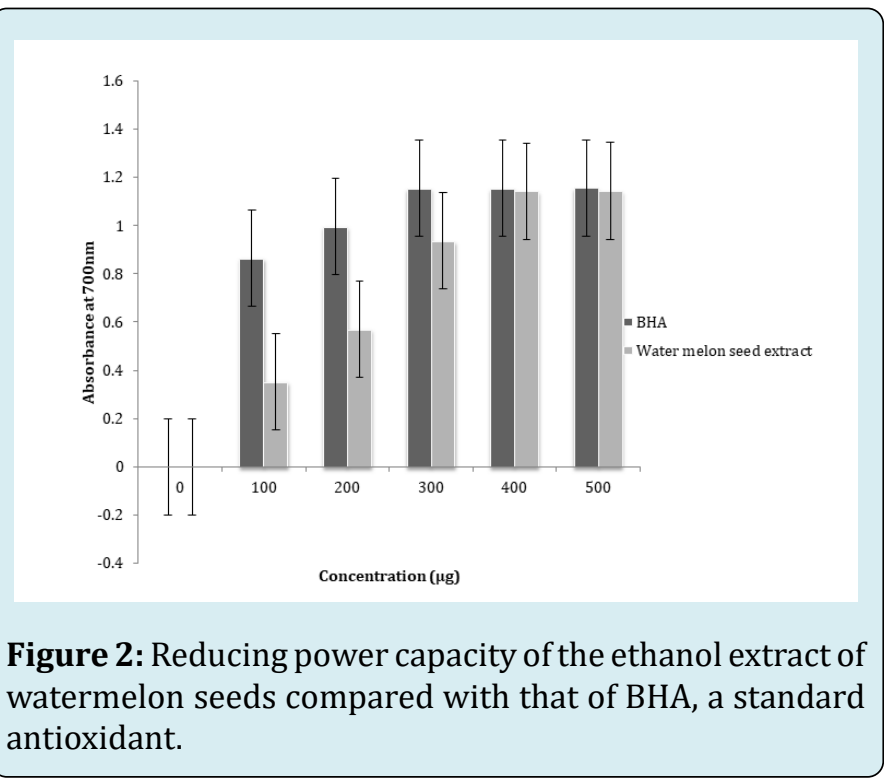




\section{International Journal of Biochemistry \& Physiology}

\section{Inhibition of Lipid Peroxidation}

The results of the potential of the ethanol extract of watermelon seeds to inhibit lipid peroxidation is shown in Figure 3. It was compared with that of BHA, a standard antioxidant. The seed extract and the standard antioxidants promoted an inhibition of lipid peroxidation with increasing concentrations. However, the percentage inhibition of lipid peroxidation by the seed extract was lower than that of the standard antioxidant though not significantly,

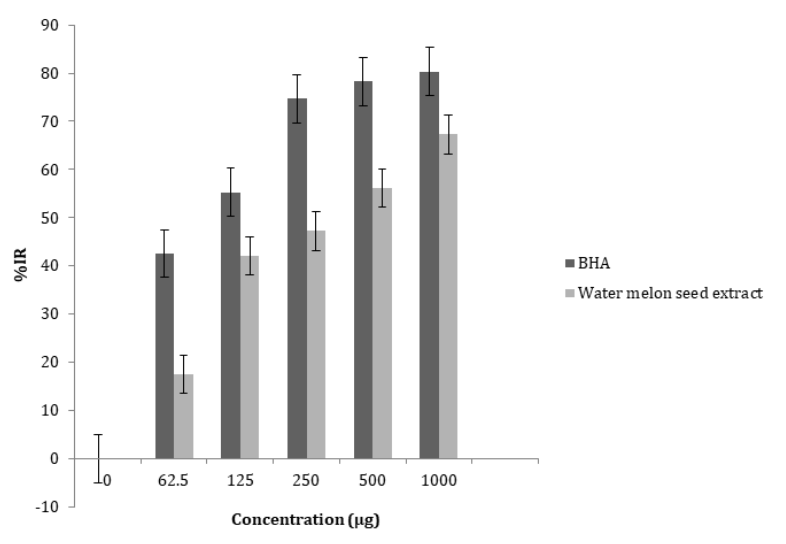

Figure 3: Inhibition of lipid peroxidation by the ethanol extract of watermelon seeds in comparison with the standard, BHA.

\section{Weight of the Experimental Animals}

Figure 4 shows the weekly weight of the animals during the experimental period. The $5 \%$ group had the highest initial weight $(140 \pm 8.5 \mathrm{~g})$ while the least initial weights was the $2 \%$ group $(98.5 \pm 1.5 \mathrm{~g})$.

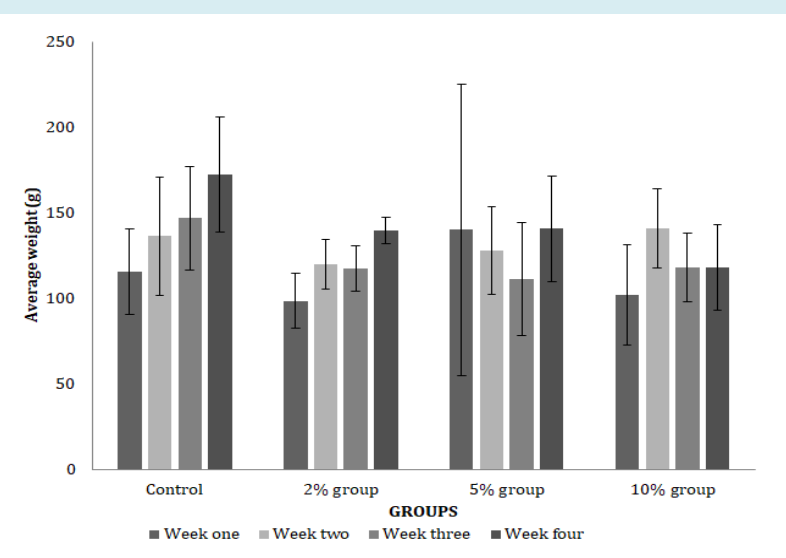

Figure 4: The weekly weights of the animals during the experimental period.
There was no significant difference in their initial weights when compared $(\mathrm{P}>0.05)$. The control group had the highest final weight $(172 \pm 3.3 \mathrm{~g})$ while the $10 \%$ group had the least final weight $(118 \pm 2.4 \mathrm{~g})$. There was no significant difference in final weight $(\mathrm{P}>0.05)$.

\section{Lipid Profile Analysis}

The effect of watermelon seed oil on serum lipid profile was compared among the groups (Figure 5). The HDL-c level of the group fed with $10 \%$ watermelon seed oil was higher than those of the other groups, but the difference was not significant $(\mathrm{p}>0.05)$

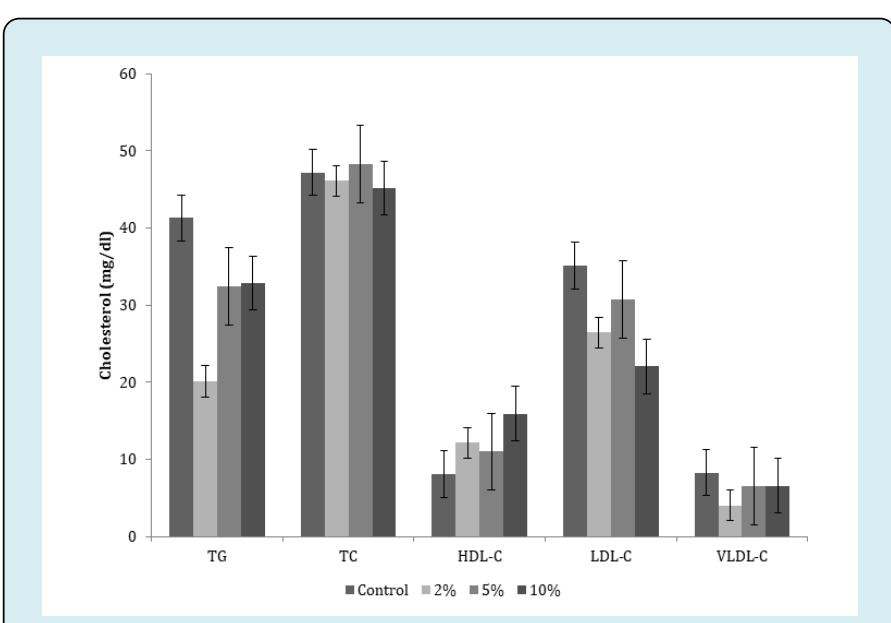

TG: Triglyceride, TC: Total Cholesterol, HDL-C: High Density Lipoprotein cholesterol, LDL-C: Low Density Lipoprotein cholesterol, VLDL-C: very low Density Lipoprotein cholesterol.

Figure 5: The effect of watermelon seed oil on serum lipid profile was compared among the groups.

\section{Discussion}

Dyslipidemia is a traditional risk factor for atherosclerosis development; it is associated closely with increased endothelial production of ROS. The result of the free radical scavenging activity of the ethanol extract of watermelon seeds (Figure 1) shows that the seed is rich in antioxidant molecule. At a concentration of $100 \mu \mathrm{g} / \mathrm{ml}$, the extract displayed a significantly higher ability to scavenge free radicals as shown by the \%RSA (33.3\%), whereas BHA at the same concentration had \%RSA of $5.1 \%$. This activity of watermelon seed extract could be as a result of its high content of polyphenols [14]. Research has shown that polyphenols are the most abundant antioxidants in fruits and plant derived beverages. These compounds present different mechanisms to exert their antioxidant property, out of which scavenging of free radicals is among [15]. Betty, et al. reported that the seed of different verities of watermelon 


\section{International Journal of Biochemistry \& Physiology}

seeds displayed percentage scavenging activity of DPPH free radicals from the range of $59.88 \%$ to $94.46 \%$ [16]. This is in agreement with the result from this study where watermelon seed extract gave $\%$ RSA of $48.6 \%$ at a concentration of $500 \mu \mathrm{g} / \mathrm{ml}$.

The reducing power potential of the seed extract was evaluated by determining its ability to reduce $\mathrm{Fe}^{3+}$ because the reducing power reflects the electron donating capacity of its bioactive compounds and may serve as a significant indicator of its antioxidant activity [17]. The results for ferric reducing activity of the extract compared to BHA used as standards is shown in Figure 2. The extract exhibited dose dependent reducing power potential which shows that it is capable of donating electron and this increased with an increase in concentration when compared to the standards BHA. This result suggests the presence of reductones in the extract. The increase is as a result of reduction of $\mathrm{Fe}^{3+}$ to $\mathrm{Fe}^{2+}$. There was no significant difference between the extract and the standard $(\mathrm{P}>0.05)$. However, the reducing power of BHA was more pronounced than that of the extract. The existence of reductones from watermelon seed is the keys to its reducing power, and these exhibit their antioxidant activities through the action of breaking the free radical chain by donating a hydrogen atom [17].

The result of the inhibition of lipid peroxidation activities of the sample are shown in Figure 3. Peroxidation of lipid is a natural phenomenon and occurs on its exposure to oxygen. In recent years, free radicals-induced lipid peroxidation has gained much importance because of its involvement in several pathological conditions such as aging, wound healing, oxygentoxicity, liver disorders, and inflammations among others [17]. Ferrous sulfate $\left(\mathrm{FeSO}_{4}\right.$ caused a significant increase in Thiobarbituric acid reactive substance (TBARS) production in goat brain homogenate. The seed extract caused a significant decrease in Fe (II)-stimulated TBARS production in the brain homogenate with increasing concentration, thus inhibited lipid peroxidation in a concentration-dependent manner. The maximum inhibitory activity was exhibited by the standard $(80.31 \%)$ at a concentration of $1000 \mu \mathrm{g} /$ $\mathrm{ml}$. This was higher than that of the seed extract, at the same concentration $(67.25 \%)$, though the difference was not significant $(\mathrm{P}>0.05)$. A possible mechanism by which it confers protection against $\mathrm{Fe}^{2+}$-induced lipid peroxidation in this homogenate can be attributed to the presence of flavonoids and phenolics found in these plants, which are well known to be chelator compounds, that may form redox inactive complexes with $\mathrm{Fe}^{2+}$, rendering this prooxidant unavailable for Fenton reaction [16]. Flavonoids and phenolics are potent antioxidants in lipid systems where they reduce oxidative modifications of membranes by restricting the access of oxidants to the bilayer and the propagation of lipid oxidation in the hydrophobic membrane matrix. The free radical scavenging by flavonoids is highly dependent on the presence of a free 3-OH present, as well as the number of hydroxyl groups presented in the structure.

From the results of the animal studies, body weight gain varied across the groups. There was a slight weight loss in the group that received $10 \%$ water melon seed oil (Figure 4). This may be attributed to the low total cholesterol fat content in the group fed with $10 \%$ seed oil. Lipid profile is a panel of blood tests that serves as an initial screening tool for abnormalities in lipids. The result of the effect of watermelon seed oil on serum lipid profile is shown in Figure 5. The control group had the highest concentration of triglyceride $(41.29 \mathrm{mg} / \mathrm{dl})$ while the group that received $2 \%$ seed oil had the lowest concentration of triglyceride $(20.09$ mg.dl). Triglycerides are the main constituents of body fat in humans and other vertebrates and are also present in the blood to enable the bidirectional transference of adipose fat and blood glucose from the liver [18]. Elevated triglycerides may contribute to pancreatitis or hardening of the arteries. This increases the risk of stroke, heart attack and heart disease [19]. High density lipoprotein cholesterol (HDL-c) is termed "good cholesterol" because its increase is correlated with cardiovascular health. The result in Figure 5 shows that the group that received $10 \%$ watermelon seed oil has the highest concentration of HDL-c $(15.92 \mathrm{mg} /$ dl) with a corresponding lower level of LDL-c $(22.03 \mathrm{mg} /$ dl) when compared with those of other groups. The control group showed a HDL-c of $8.08 \mathrm{mg} / \mathrm{dl}$ which is the lowest observed in all the groups. The LDL-c of the control group was also the highest observed in all the groups $(35.11 \mathrm{mg} /$ dl). Watermelon seed oil was reported to contain $68.3 \%$ linoleic acid [20]. Linoleic acid is an unsaturated fatty acid that is metabolized via several routes and research suggests that it is probable that a metabolite, rather than linoleic acid itself, is responsible for its cholesterol-lowering effect [21]. Watermelon seeds also contain citrulline, an amino acid that have been proven to have incremental effect on HDL-c content [22]. This observation is in agreement with the cholesterol lowering effect reported on egusi melon seed oil [23]. Egusi melon is popularly used for making egusi soup in Nigeria and other African countries. Elevated concentration of tissue cholesterol following consumption of a high fat diet could lead to increased susceptibility of tissues to lipid peroxidation, unless there is presence of adequate amount of antioxidants [23]. Watermelon seed is rich in such antioxidants as seen from the result of its antioxidant activity (Figures 1-3), thus this could contribute to its hypocholesterolemic effect. Water melon seed oil also contains tocotrienol [24]. Human studies have also confirmed that tocotrienols of palm oil have the ability to reduce the risk of stroke, arteriosclerosis, and ischemic heart disease by reversing the blockage of carotid artery and platelet aggregation [23]. 


\section{International Journal of Biochemistry \& Physiology}

\section{Conclusion}

The results obtained from this study show that watermelon seeds have great potentials. The in vitro antioxidant activity could be attributed to the high content of polyphenols. Antioxidant action of phenolic compounds is due to their high tendency to chelate metals. They possess hydroxyl and carboxyl groups which are able to bind particularly iron and copper, thus it could offer protection against lipid peroxidation and its associated diseases. The hypocholesterolemic effect also suggests that the seed oil could be used in the management of hyperlipidemia. Thus, this study should be extended to human subjects, perhaps, the result obtained could encourage the consumption of watermelon seed along with the fruit pulp.

\section{References}

1. Oguejiofor OC, Onwukwe CH, Odenigbo CU (2012) Dyslipidemia in Nigeria: Prevalence and pattern. Annals of African Medicine 11(4): 197-202.

2. Niva S, Ossie S in Encyclopedia of Cancer (2019) Prevention and Control: Nutrition, Obesity, and Metabolism. $3^{\text {rd }}$ (Edn.), Encyclopedia of cancer, pp: 278291.

3. Willcox JK, Ash SL, Catignani GL (2004) Antioxidants and prevention of chronic disease. Crit Rev Food Sci Nutr 44(4): 275-295.

4. Pham-Huy LA, He H, Pham-Huyc C (2008) Free Radicals, Antioxidants in Disease and Health. International Journal of Biomedical Science 4(2): 89-96.

5. Manfredi R, Jelena K, Kaspar B, Giatgen S, Giovam BR, et al. ( 2009) Atherogenic dyslipidemia and oxidative stress: a new look. Transl Res 153(5): 217-223.

6. Barros L, Soraia F, Baptista P, Cristina F, Miguel VB, et al. (2007) Antioxidant activity of Agaricus sp. mushrooms by chemical, biochemical and electrochemical assays. Food Chemistry 111(1): 61-66.

7. Roberts LJ, Moore K (2003) Measurement of Lipid Peroxidation. Free Radic Res 28(6): 659-671.

8. Balz F, Roland S, Bruce NA (1988) Antioxidant defenses and lipid peroxidation in human blood plasma. Proceedings of National Academy of Science USA 85: 9748-9752.

9. National Cholesterol Education Program (NCEP) Expert Panel On Detection, E (2002) Third Report of the National Cholesterol Education Program (NCEP) Expert Panel on Detection, Evaluation and Treatment of High
Blood Cholesterol in Adults (Adult Treatment Panel III) final report. Circulation 106(25): 3143-3421.

10. Balakrishnan N, Varugluse T, Matthew SP (2015) A review on Citrullus lanatus Thunb, International Journal of Pharmaceutical Sciences Letters 5(3): 558-562.

11. El-Adawy TA, Taha KM (2001) Characteristics and composition of watermelon, pumpkin and paprika seed oils and flours. J Agric Food Chem 49(3): 1253-1259.

12. Ebrahimzadem MA, Jashidi M, Shabani E, Hashemi Z (2014) Evaluation of three methods for the extraction of antioxidants from leaf and aerial parts of Lythrum salicaria L. (Lythraceae). International food research journal 21(2): 783-788.

13. Sidhu D, Naugler C (2012) Fasting Time and Lipid Levels in a Community Based Population. Arch Intern Med 172(22): 1-4.

14. Nwachoko N, Owhonda N (2019) Proximate, Phytochemical and Antidiarrhoea properties of water melon seeds (Citrullus lanatus). Archives of Nutrition and Public Health 1(1).

15. Juliana MM, Daniel F (2014) Chapter 20 Polphenol Antiioxidants from natural sources and contribution to Health promotion. Polyphenols in human Health and Disease 1: 253-265.

16. Betty T, Jacob KA, Faustina DW, Elsa IO (2016) Watermelon seeds as food: Nutrient Composition, Phytochemicals and Antioxidant Activity. International Journal of Nutrition and Food Sciences 5(2): 139-144.

17. Elekofehinti OO, Kamdem JP, Bolingon AA, Athayde ML, Lopes SR, etal. (2013) African Eggplant (Solanum Anguivi Lam.) fruit with bioactive polyphenolic compounds exerts In Vitro antioxidant aroperties and inhibits $\mathrm{Ca}^{2+}$ Induced Mitochondrial Swelling. Asian Pacific Journal of Tropical Biomedicine 3(10): 757-766.

18. Lampe MA, Burlingame AL, Whitney J, Williams ML, Brown B, et al. (1983) Human stratum corneum lipids: characterization and regional variations. J lipid Res 24(2): 120-130.

19. Sally R (2018) Hypertriglyceridemia cause and symptoms. News medical life sciences.

20. Zahra MB, Ali ASK (2010) Characteristics and Composition of Watermelon Seed Oil and Solvent Extraction Parameters Effects. Journal of the American Oil Chemists' Society 87: 667-671.

21. Horrobin DF, Huang YS (1987) The role of linoleic acid and 


\section{International Journal of Biochemistry \& Physiology}

its metabolites in the lowering of plasma cholesterol and the prevention of cardiovascular disease. International Journal of cardiology 17(3): 241-255.

22. Amal AA, Hanana MF, Hala FA (2011) The Effect of L-arginine or L-citrulline supplementation on biochemical parameters and vascular aortic wall in highfat and high-cholesterol-fed rats. Cell Biochem Funct 29(5): 414-428.

23. Olarewaju MO, George OE, Godwin CO, Blessing OI
(2010) Palm and Egusi melon oils lower serum and liver lipid profile and improve antioxidant activity in rats fed a high fat diet. International journal of Medicine and Medical Sciences 3(2): 47-51.

24. Pawel G, Arianne S, Dalija S (2015) Tocopherols and tocotrienols profile in seed oils recovered from industrial fruit by-products: Rapid separation of $\alpha / \beta /$ $\gamma / \delta$ homologues b RP-HPLC/FLD method. European Journal of Lipid Science and Technology 117(6). 